Revista de Estudios Histórico-Jurídicos

[Sección historia del pensamiento político]

XXXVIII (Valparaíso, Chile, 2016)

[pp. 421 - 442]

\title{
La IDEA de Estado MOderno bajo la Mira CONFESIONAL: TRES CENSURAS A "DE IURE NATURAE ET gentium" (1672) DE SAMuel PufendorF
}

[The idea of modern state under the confessional view: Three censorships to "De jure naturae et gentium" (1672) of Samuel Pufendorf]

\author{
Fernando Pérez GodOY*
}

\section{RESUMEN}

El presente artículo tiene como objetivo reconstruir los procesos de censura a la obra De Iure naturae et gentium (Lund 1672) del jurista alemán Samuel Pufendorf. Específicamente nos concentramos en los puntos comunes de controversia y fricción al interior de la intelectualidad protestante y católica que generó la idea de Estado propuesta en esta obra en el contexto de temprana ilustración alemana. Como intentamos mostrar, los procesos de censura de libros componen parte importante de la historia intelectual del Estado Moderno y también permiten comprender los procesos de circulación de ideas e intercambio científico entre distintas culturas jurídicas en la época moderna.

Palabras clave

Censura - Derecho Natural y Gentes

- Pufendorf-Estado Moderno.
Abstract

This article aims to reconstruct the process of censorship to the work De Iure Naturae et Gentium (Lund 1672) of the German jurist Samuel Pufendorf. Specifically we focus on the common points of controversy and friction within the Protestant and Catholic intellectual culture that generated the idea of state proposed in this work in context of early German enlightenment. As we try to prove, the processes of censorship of books make up an important part of the intellectual history of the modern state and also allow understand the processes of circulation of ideas and scientific exchange between different legal cultures in the modern times.

\section{KeYWordS}

Censorship - Natural Law - Pufendorf Modern State.

RECiBIDO el 7 y ACEPTADO el 24 de junio de 2016

* Doctor phil. Universidad de Maguncia, Alemania. Dirección postal: Viana 967, Viña del Mar. Correo electrónico: fernandoperezgodoy@gmail.com. 


\section{INTRODUCCIÓN}

En 1785 declaraba el profesor de prima de leyes José Miguel Lastarria ante el tribunal de la Inquisición en Lima que ya había olvidado al Pufendorf y que todas sus obras de Montesquieu, Raynal, Maquiavelo entre otras habían sido quemadas $^{1}$. Los oficiales de la Inquisición habían ordenado cerrar su cátedra de derecho natural y gentes en la Universidad de San Felipe, luego de que Lastarria comenzara a enseñar las novedosas tesis planteadas por el jurista sajón en sus obras Iuresprudentia universalis y sobre todo De Iure Naturae et Gentium ${ }^{2}$. Los planteamientos de Pufendorf en esta disciplina, argumentaban en el Santo Oficio, se dirigían contra la verdadera religión y la constitución de la monarquía. Solamente la intervención del Virrey peruano evitó que Lastarria terminara en cárcel por la lectura y enseñanza de un autor declarado hereje y cuyas obras no podían circular entre los católicos ${ }^{3}$. En efecto, De iure naturae et gentium libro octo (Lund, 1672) fue condenada por la censura de libros de la Inquisición española en el año 1714 y el compendio de esta obra De officio hominis et civis (Lund, 1673) en $1752^{4}$. Pero la censura de la obra del jurista luterano en el siglo XVIII

${ }^{1}$ Medina, José Toribio, Historia del Tribunal del Santo Oficio de la Inquisición en Chile (Santiago, Fondo Bibliográfico J. T. Medina, 1952), p. 632: "Sin esta protección, de nada le habría servido la protección judicial para escapar del celo de los agentes del Santo Oficio, por más que pudiera alegar también en su favor, como alegaba, la Real orden de 10 de agosto de 1785 que habia perdonado u olvidado a Pufendorf, al mandar que en el Perú y sus dependencias, se recogieran y se quemaran el Belisario de Marmontel, las obras de Montesquieu, Linguet, Raynal, Maquiavelo, Monsieur Legros, y la Enciclopedia; y se tomaran otras medidas para evitar la publicación e introducción de papeles prohibidos por el Santo tribunal y el Estado". Si bien la cátedra de ius naturae et gentium fue introducida en el imperio español durante la última parte del siglo XVIII, no disponemos de mayor información de su implementación en Chile colonial. Gajardo VillarRoel, Enrique, Reseña histórica de la enseñanza superior en Chile y del estudio del derecho de gentes, antes y después de la independencia (Santiago de Chile, Taller Imprenta, 1928), pp. 26-28; Silva Castro, Raúl, Fundación del Instituto Nacional (1810-1813) (Santiago, 1953), p. 20; AмUNÁTEGUI, Domingo, Los primeros años del Instituto Nacional (1813-1836) (Santiago, Imprenta Cervantes, 1888); SPIEWAK, Martin, Das ferne Echo der Vernunft: das höhere Bildungswesen in Hispanoamerika im Zeitalter der Aufklärung (Münster, Hamburger Ibero-Amerika-Studien 3, 1993), p. 31.

${ }^{2}$ Medina, José Toribio, cit. (n 1), p. 630. "En la Universidad de San Felipe, cuenta su nieto don José Victorino Lastarria, aquel no se limitó a su catedra de prima de leyes sino que se avanzó a revelar a sus discipulos la ciencia de Pufendorf. Poseedor de los Elementos de jurisprudencia universal de este sabio, y especialmente del Tratado de derecho natural y de gentes, dictó sus lecciones en español $y$ las explicó con un atractivo poderoso, merced a sus distinguidas dotes oratorias".

3 Ibíd., p. 629: "la universdad no sería otra cosa que un alcazar para defender la religion, propagar la fé i conservar la sociedad politica".

${ }^{4}$ Defourneaux, Marcelin, L'inquisition espagnole et les livres français au XVIIIème siècle (París, Presses Universitaires de France, 1963), p. 225; SANTO Oficio DE LA INQUISICIÓn, Índice General de los libros prohibidos, compuesto del indice último de los libros probibidos y mandados expurgar hasta fin de diciembre de 1789 por el señor inquisidor general y señores del supremo consejo de la Santa General Inquisición, de los suplementos del mismo, que alcanzan hasta 25 de agosto de 1805, y además de un index librorum prohitorum juxta exemplar romanum jessu ss. d. n. Editum anno MDCCCXXXV, en el van intercalados en sus respectivos lugares los prohibidos hasta fin de 1842 (Madrid, 1844); OfICIO DE LA INQUISICIÓN ESPAÑOLA, Indice de los libros probibidos por el Santo Oficio de la Inquisición Española, desde su primer decreto hasta el último, que expidió en 
no se reduce al mundo católico. En el manual sobre el desarrollo histórico de la ciencia del Derecho Natural y Gentes, Kurzer Entwurf einer Historie des Naturund Völker-Rechts: nebst einigen Anmerkungen über die Unvollkommenheiten der natürlichen Rechtsgelehrsamkeit (Leipzig, 1759), declara el profesor de la Universidad de Wittenberg, Georg Wiesand, que su colega Samuel Pufendorf había sido el desatador de las llamadas guerras intelectuales de Europa ${ }^{5}$. Partiendo de los datos del ilustrado alemán Christian Thomasius habían durado estas guerras hasta 1708 catorce años ininterrumpidos ${ }^{6}$, luego de que Pufendorf publicase en 1672 su mencionado tratado De iure naturae et gentium en Lund, Suecia. En la segunda mitad del siglo XVIII, tales antagonismos no habían sido superados. La resonancia de este tratado había sobrepasado la mera discusión polémica, la cual marcó en un comienzo la disputa confesional sobre el ius naturae y más bien experimentaron los tratados del jurista luterano una amplia circulación y recepción primero en Universidades y cortes principescas en el Sacro Imperio Romano de la Nación Alemana a fines del siglo XVII, luego en toda Europa ${ }^{7}$, hasta alcanzar incluso las colonias del imperio español ${ }^{8}$. Principal motivo de esta amplísima circulación, así nuestra propuesta, fue el hecho de que los progresos realizados por Pufendorf en el desarrollo de la ciencia iusnaturalista fueron recibidos como una importante contribución para la conformación de las ciencias estatales y civiles, de cuyos conocimientos podían bien servirse gobiernos, diplomáticos, y cuerpos de funcionarios del Estado absolutista moderno europeo y más precisamente los Estados principescos territoriales alemanes ${ }^{9}$. Además y con mayor importancia a nuestro entender, el texto de Pufendorf pasó a ser parte del cuerpo doctrinario de las fuentes del derecho de gentes del siglo XVIII y contribuyó a la creación de una nueva normatividad internacional que buscaba reemplazar a los sistemas

29 de mayo de 1819, y por los obispos españoles desde esta fecha hasta fin de diciembre de 1872 (Madrid, Imprenta de D. Antonio Perez Dubruij, 1873), p. 346.

${ }^{5}$ WIESAND, Georg, Kurzer Entwurf einer Historie des Natur- und Völker-Rechts: nebst einigen Anmerkungen über die Unvollkommenheiten der natürlichen Rechtsgelehrsamkeit (Leipzig, 1759), p. 3.

${ }^{6}$ Thomasius, Christian, Historia algo más extensa del Derecho Natural de Christian Thomasius (Halle 1719, trad. cast. Madrid, Tecnos, 1998), XIII, p 11.

7 OTHмеR, Sieglinde C., Berlin und die Verbreitung des Naturrechts in Europa: kultur-und sozialgeschichtliche Studien zu Jean Barbeyracs Pufendorf-Übersetzungen und eine Analyse seiner Leserschaft (Berlin, De Gruyter, 1970).

${ }^{8}$ Pérez Godoy, Fernando, La presencia de las ideas politicas de Samuel Pufendorf durante la independencia de Chile en Revista Derecho y Humanidades 17 (2011), pp. 151-167.

9 Una primera constatación de este fenomeno en Kaltenborn, Carl von, Die Vorläufer des Hugo Grotius auf dem Gebiete des Jus naturae et gentium (Leipzig, Verlag von Gustav Mayer, 1848); Fernández Sarasola, Ignacio, La dimensión politica de Jovellanos, en Vlarde, Juan, Jovellanos: el hombre que soñó España (Madrid, Encuentro, 2012), p. 113: "En la formación de este pacto hallamos algunas de las enseñas de la Ilustración Liberal, aunque muy posiblemente también haya influencia de Pufendorf: el pacto social es, a un tiempo, origen de una nueva sociedad y del Estado, es decir, mejora la situación social y lo hace constituyendo el poder público"; Bornstein, Félix, José Rodríguez Campomanes. Los límites del reformismo ilustrado, en Revista de Estudios Políticos (Nueva Época) 118 (2002), p. 106; MarTínez Albiach, Alfredo, Grocio- Pufendorf ante Mayáns-Campomanes, en Cuadernos de Estudios del Siglo XVIII, CES 6-7 (1996-1997). 
jurídicos de pretensión universal canónico y romano. La historiografía jurídica ha llamado con razón a esta etapa de la historia del ius naturae et gentium en el siglo XVIII como una fase de "Applikation y Ausdifferenzierung" de la doctrina iusnaturalista ${ }^{10}$ y naturalmente incluye la contribución científica de una serie de pensadores y juristas europeos, los cuales sobrepasan la capacidad de este escrito. Como intentaremos mostrar a través de los procesos de censuras a la obra máxima de Pufendorf, el derecho natural y de gentes experimenta un claro desplazamiento de su campo de ocupación científica desde la filosofía moral a la investigación del proceso de formación del Estado territorial moderno. Como hemos propuesto, este paso fue decisivo para la exitosa comunicación de la concepción de Estado de Pufendorf en un medio cultural e intelectual europeo regido por el aristotelismo y la escolástica ${ }^{11}$.

\section{Pufendorf en el “IndeX” protestante}

Como el texto de Wiesand o Thomasius dan testimonio, es punto común entre los juristas europeos del siglo XVIII destacar a las obras de Samuel Pufendorf y del jurista holandés Hugo Grocio como punto de partida de las reflexiones científicas y académicas sobre la autonomía de la disciplina del ius naturae et gentium durante la época de la Ilustración ${ }^{12}$. Es sin embargo para destacar que la consolidación de un cuerpo de conocimiento sistemático sobre esta ciencia iusracionalista fue el resultado de una serie de procesos culturales de circulación, censura y readaptación tanto en el ámbito católico como en el protestante. Al igual que en los casos de la Santa Congregación Romana para la Defensa de la Fe y el Tribunal del Santo Oficio de la Inquisición Española, las obras iusnaturalistas de juristas luteranos como Pufendorf o Thomasius fueron censuradas en el mismo mundo intelectual protestante. En el género de los escritos polémicos (Pasquillschriften) representa efectivamente la controversia sobre la teoría jurídica de Pufendorf uno de los temas más discutidos a finales del siglo XVII en el espacio medio europeo. Se habla en efecto de una guerra de plumas ${ }^{13}$. La bibliografía sobre Pufendorf aparecida en

10 Fiorillo, Vanda/ Grunert, Frank, Das Naturrecht der Geselligkeit: Anthropologie, Recht und Politik im 18. Jahrhundert (Berlin, Duncker \& Humblot, 2009), p. 5.

11 STOLLEIS, Michael, Judicial Interpretation in Transition from the Ancien Régime to Constitutionalism en STOLLEIS, Michael, MorIGIWA, Yasutomo, HalPÉRIN, Jean Louis, Interpretation of Law in the Age of Enlightenment. From the Rule of the King to the Rule of Law (London, Springer, 2011), p. 8; BÖCKENFÖRDE, Ernst-Wolfgang, Geschichte der Rechts-und Staatsphilosophie, Antike und Mittelalter (Tübingen, UTB, 2002), pp. 172-184.

12 Benme, Thomas, Samuel von Pufendorf: Naturrecht und Staat. Eine Analyse und Interpretation seiner Theorie, ihrer Grundlagen und Probleme (Göttingen, Vandenhoeck \& Ruprecht, 1995), pp. 183-188; Zurbuchen, Simon, Samuel Pufendorfs Theorie der Staatsformen und ihre Bedeutung für die Theorie der modernen Republik, en HüNING, Dieter, Naturrecht und Staatstheorie bei Samuel Pufendorf(Baden-Baden, Nomos, 2009), p. 138.

13 DöRING, Detlef, Pufendorf in der Welt des 17. Jahrhunderts. Untersuchungen zur Biographie Pufendorfs und zu seinem Wirken als Politiker und Theologe (Frankfurt am Main, Vittorio Klostermann, 2012), p. 104: "Ihren Beginn fand die Kontroverse in Schweden, wo Pufendorf seit 1668 als Professor an der Universität Lund lebte. Trotzdem ist die Eris Scandica eigentlich 
2012 por Detlef Döring trae a colación la historia de la impresión, difusión y censura de las obras del jurista alemán en Kursachsen luego de la publicación de De Iure Naturae Gentium $1672^{14}$. Kursachsen y especialmente Leipzig jugaron un rol central en la reimpresión y reedición de traducciones alemanas de los escritos de Pufendorf ${ }^{15}$. Leipzig fue un campo de tensión entre las tendencias científicas y ortodoxas y representó un reducto académico, el cual Pufendorf difícilmente pudo penetrar a consecuencia del Aristotelismo teórico dominante (metafísica escolar $)^{16}$. Es conocido en la historiografía el hecho que Pufendorf, exactamente como su hermano Esaias (1628-1689), se había decepcionado ya en su época de estudiante en Leipzig ${ }^{17}$ de la estrecha relación académica entre teoría y teología ${ }^{18}$, de tal modo que prefirió proseguir sus estudios de política y derecho bajo la dirección del profesor cartesiano Edward Weigel en Jena. Para el historiador del derecho E. Wolff fue Weigel uno de los primeros académicos en implementar el método cartesiano demostrativo en la filosofía alemana moderna ${ }^{19}$. Su influencia en el pensamiento jurídico de Pufendorf es clara y determinante según nuestro parecer para entender la desteologización del ius naturae en su obra, pero también para comprender la reflexión científica del jurista luterano sobre la formación del Estado territorial moderno como fenómeno exclusivamente jurídico ${ }^{20}$. Es este punto el cual quisiéramos ahondar a lo largo de este escrito, la definición

eine 'Eris Germanica', denn die meisten und wichtigsten Gegner, aber auch Verteidiger Pufendorfs wirken in Deutschland'.

14 PufEndorf, Samuel, De jure naturae et gentium libri octo (Londini Scanorum, Adam Junghans, 1672).

${ }^{15}$ DöRING, Detlef, Samuel Pufendorf und die Leipziger Gelehrtengesellschaften in der Mitte des 17. Jahrhunderts en Sitzungsberichte der Sächsischen Akademie der Wissenschaften zu Leipzig, Bd. 129, Heft 2 (1989), p. 130: "Andererseits besitzt Leipzig durch den hier veranstalteten Nachdruck verschiedener Streitschriften und durch die Herausgabe deutscher Übersetzungen zentraler Arbeiten Pufendorfs ein nicht geringes Verdienst bei der Verbreitung der an der Herausbildung des modernen Europas maßgeblich beteiligten Ideen des großen sächsischen Gelehrten".

16 Glafey, Adam Friedrich, Vollständigen Geschichte des Rechts der Vernunft (Leipzig, 1739), p. 206.

17 Wolf, Erik, Grosse Rechtdenker der deutschen Geistesgeschichte (Tübingen. J. C. B. Mohr 1951), p. 314: "Schon im ersten Semester fïhlte sich der noch jugendliche Student vom Dogmatizismus und der Unduldsamkeit seiner orthodox lutherischen Hochschulleherer in Leipzig - der Hochburg des protestantischen Aristotelismus-abgestossen".

${ }_{18}$ Hunter, Ian, Saunders, David, Introduction, en Pufendorf, Samuel, The whole duty of man according to the law of nature (London 1691, trad. ingl. Indianapolis, Liberty Fund, 2003), p. xi: "Pufendorf continued his education at the universities of Leipzig and Jena (1650-58). At Leipzig his thoughts of a clerical career soon evaporated, the result of his exposure to Lutheran orthodoxy in its uncompromising Protestant-scholastic form".

19 Wolf, Erik, cit. (n 17), p. 316: "Durch die Leistungen seines genialen Schülers Leibniz geriet Weigel unverdient in Vergessenheit. Als erster deutscher Vertreter einer mathematisch demonstrierenden Methode des Philosophierens und las entschiedener Verfechter des Gedankens einer von theologischen Voraussetzungen freien Kultur-und Moralphilosophie, hat er auf die geistige Entwicklung im Deutschland des ausgehenden 17. und beginnenden 18. Jabrhunderts stark gewirkt".

20 Pufendorf confiesa a Weigel en carta de 17.4.1659 que estando en prisión durante 1659 en Kopenhagen, habría llegado a determinación de abandonar la vía antigua y seguir las tendencias grocianas. Pufendorf, Samuel, Briefwechsel. Gesammelte Werke, (1673, Berlin, Akademie Verlag, 1996), p. 14. 
contractualista de Estado de Pufendorf en la obra mencionada es clara: para dar forma a un nuevo Estado se necesitan duo pacta \& unum decretum. Esto es, por un primer pacto acuerda cada hombre superar el estado libre de naturaleza para someterse a una unión única y perpetua, luego por un decreto definen libremente la mejor forma de Estado (forma regiminis), para finalmente por un último pacto crear una autoridad que garantiza la seguridad común y salutatis de los súbditos (civitas perfecta) mediante obediencia. Para muchos de sus colegas juristas y sobre todo para el medio teológico europeo esta definición representó mucho tiempo una herejía jurídica ${ }^{21}$, hasta finalmente ser aceptada como componente central de la teoría del Estado de la Ilustración. La historia intelectual de esta transición está marcada por una serie de disputas académicas hasta hora poco estudiadas.

Pufendorf tenía experiencia en la confrontación literaria cuando participó al servicio de los intereses del príncipe Karl Ludwig en la disputa por los derechos de caza con el elector de Maguncia en $1665^{22}$. Sin embargo, así Döring, Pufendorf sólo será conocido en el mundo pre ilustrado alemán luego de la aparición de $D e$ Iure Naturae (1672 Lund). Esta obra le dio al jurista luterano su popularidad y reconocimiento en la republica literari de entonces ${ }^{23}$. Aunque su escrito histórico publicado bajo el nombre del viajero italiano Severino de Monzambano ${ }^{24}$ le otorgó popularidad en toda Europa y desde 1667 se convirtió en un bestseller en la publicista imperial ${ }^{25}$, se dudaba hasta finales del siglo XVII quién era el autor de semejante escrito polémico ${ }^{26}$. Una traducción alemana de este texto aparecido en 1710 incluía una remarkable historie dieses Buchs, una destacada historia de este libro $^{27}$, en la cual los editores intentan probar que detrás de la máscara del viajero italiano Severino Monzambano se escondía finalmente Samuel Pufen-

21 PuFENDORF, Samuel, De officio hominis et civis juxta legem naturalem. Gesammelte Werke, (Lund 1673, Bd. 2. Reimp. Berlin 1997), Lib. II, Caput VI, De interna civitatum structura, $\$ 1$, p. 70; Huesbe, Marco, La teoría politica de Samuel Pufendorf a través de su comentario a la constitución del imperio romano-germánico (1667), en Revista de Estudios Histórico-Jurídicos 31 (2009), p. 439.

22 El historiador Joachim Radkau ha planteado la importancia de la intervención de la naciente autoridad política en los bosques y los derechos a explotación en el proceso de formación del Estado moderno. RADKAU, Joachim, Holz, Wie ein Naturstoff Geschichte schreibt (München, Ökom, 2012), p. 100.

23 Schorn SchütTe, Luise, Kommunikation über Politik im Europa der Frühen Neuzeit, en Jahrbuch des Historischen Kollegs (2007), p. 8: "Wichtig ist die Einsicht, dass es gemeinsame akademische Formen einer europäischen Gelehrtenkultur gegeben hat, die für die Entfaltung, Verbreitung und Verzahnung juristischer und theologischer Sprachen in der europäischen politischen Kommunikation eine gewichtige Rolle gespielt haben".

24 Monzambano, Severinus, De statu imperii germanici ab Laelium fratem, dominum Trezolani, liber unus (Genf, Den Haag, 1667).

25 HaAs, Julia, Die Reichstheorie in Pufendorfs "Severinus de Monzambano" Monstrositätsthese und Rechtsdebatte im Spiegel der politisch-juristischen Literatur von 1667 bis heute (Berlin, Duncker \& Humbolt, 2007), p. 45.

26 Pufendorf, Samuel, Briefwechsel, cit. (n 20), pp. 86-87. Tbn. pp. 190-193.

${ }^{27}$ Gledirsch, Johann Ludwig, Weidmann, M. W. (eds.), Remarkable historie dieses Buchs, en Puffendorf, Samuel, Kurzer, doch gründlicher Bericht von dem Zustande d. H. R. Reichs Teutscher Nation in Lateinischer Sprache unter dem Titel Severin von Monzambano herausgegeben, (1667, trad. alem. Leipzig, 1710). 
dorf $^{28}$. Según los editores, la autoría del texto debía ser de Pufendorf, porque el autor de tal tratado no podía venir de Italia, toda vez que en ese país el modo de pensamiento filosófico y el estilo presentado en tal libro no eran aún conocidos. Difícilmente es imaginable, agregan los editores, que un italiano manejase las nuevas opiniones y haya abandonado los principia aristotelica. Para los editores, en esta nación (Italia) dominaban las antiguas teorías y por último un italiano jamás dejaría imprimir sus obras en la ciudad de La Haya, de manera que el autor debía ser necesariamente Samuel Pufendorf ${ }^{29}$. Si la autoría del jurista luterano sobre la obra Constitución del Imperio Alemán era discutida, no lo fue en el caso de De Iure Naturae et gentium libro octo ${ }^{30}$, la cual aparece como su obra más influyente en la Reichpublizistik al tratarse para su época de un verdadero sistema teórico sobre esta disciplina ${ }^{31}$.

Como hemos indicado, en su mayor parte escrito en Heidelberg y finalmente publicado en Lund, debió el tratado principal de Pufendorf luchar contra los intentos de censura de teólogos de Leipzig, Gießen, Dresden y Lund. El jurista alemán respondió con dos hasta ahora apenas tratadas cartas Apologie pro se et suo libro 1674 y Epistola ad Adamum Scherzerum (Helmstedt 1674-1675) (2) $^{32}$ El índex que analizaremos a continuación y es presentado por primera vez en castellano, es el redactado por Joshua Schwarz, el pro canciller y obispo de Lund Peter Winstrup y el jurista alemán Nikolaus Beckmann, Index quorundam novitatum (Gießen, 1673), en el cual se detallan 31 errores de Pufendorf contra el decálogo y la ortodoxia protestante ${ }^{33}$. Con ello comienza la querella académica denominada Eris Scandica ${ }^{34}$, una larga disputa entre numerosos detractores y seguidores de las

${ }^{28}$ Ibíd., p.11.

${ }^{29}$ Ibíd, p. 4.

30 Thomasius, Christian, Historia, cit. (n 6), p. 137: De este género es la doctrina sobre la especificidad de lo que concierne a la moral en general, sobre los principios de las acciones humanas, su naturaleza y sus tendencias, sobre el principio de moralidad, sobre las leyes en general, sobre el estado, la condición y naturaleza del hombre respecto de las acciones morales, sobre la naturaleza y requisitos de los pactos, sobre el origen y la naturaleza del lenguaje y del dominio, sobre los modos de adquisición, sobre el precio de las cosas, sobre la naturaleza y la variedad de los contratos, sobre el origen y la naturaleza tanto de las primeras sociedades como de las comunidades ciudadanas, sobre el poder civil, sus deberes y tendencias, y si hay otras.

31 HüNING, Dieter, Naturrecht und Staatstheorie bei Samuel Pufendorf (Baden-Baden, Nomos, 2009), p.12: "Dieser durchschlagende Erfolg verdankt sich-neben Pufendorfs Systematisierung des moralphilosophischen Stoffe-vor allem seinen vielfältigen systematischen Innovationen".

32 Pufendorf, Samuel, Apologie pro se et suo libro, adversus autorem libelli famosi, cui titulus, index quarundam novitatum, quas Dn. Samuel Pufendorf libro suo de iure Natura \& Gentium contra orthodoxa fudamenta Londini edidit. Germanopoli, 1674, Samuelis Pufendorfii Epistola ad... Joh. Adamum Scherzerum, super censura quapiam in librum suum inique lata. (Lund, Hardervici, 1674).

33 Döring, Detlef, Pufendorf in der Welt, cit. (n. 13), p. 106.

34 Pufendorf, Samuel, Eris scandica, (Frankfurt am Main, Friedrich Knoch, 1688). Esta controversia esta dividia en la colección compuesta por los siguientes escritos: Apologia pro se et suo libro, Adverfus Autorem Libelli Famosi, cui titulus, Index quarundam Novitatum, quas Dn. Samuel Pufendorflibro suo de Jure Natura \& Gentium contra orthodoxa fundamenta Londini edidit (Leipzig, 1674); Epistola ad Adamum Scherzerum (Göttingen, 1674); Epistola ad amicos suos per Germania, super libello famoso, quem Nicolaus Beckmannus quondam Profeffor in Academia 
tesis de Pufendorf compilados en 1686-1688, polémica que como hemos sostenido marcó considerablemente la percepción de las obras del jurista sajón en el imperio alemán y determinó la circulación de su pensamiento en época de Ilustración. En el proceso de censura de De Iure Naturae de 1673 (Hactenus Lundensis Index Novitatum) fueron condenadas por el índex lundinense las siguientes tesis propuestas por Pufendorf sobre los fundamentos de su teoría jurídica:

(De Theologia in genere). Para Pufendorf la salvación queda fuera del ámbito de validez del derecho natural. Según la censura Salvatio puede ser alcanzada solo a través de revelatio divina spectantia. El ius para Pufendorf puede ser entendido en consecuencia a través de lumine rationis y tiene como objetivo tranqulitas huius vitae $e^{35}$.

El Estado debe reflejar la doctrina la cual armonice con su utilidad y objetivos. Pufendorf explica esto no a través de la scientia humana, sino a través del cultum Dei.

(De Scriptura Sacra). La doctrina de statu integritatis \& corruptionis propuesta por el jurista sajón no es correcta en consideración a la autoridad de las santas escrituras.

Negación de Dios como autor de las leyes. La ley puede ser creada en su teoría sin intercesión de Dios ${ }^{36}$.

Dios es obedecido no a consecuencia de su essentia sino a consecuencia de su potesta, voluntae y benefitia. La ley es obedecida más por la voluntad de las personas que por la voluntad de Dios mismo ${ }^{37}$.

El estado de naturaleza sería en Pufendorf uno de longe miserrima y los hombres dispondrían en este estado la capacidad de entia fisica y entia moralia ${ }^{38}$.

(De libero arbitrio). La capacidad de juicio y la facultad de comprensión se

Carolina, nunc vero cum infamia inde relegatus, mentito nomine Verdici Constantis fuperiori anno diffeminavit (1676, Petri Dunaei); Epistola ad Virum Famosißimum, Nicolaum Beckmannum, totius Germaniae Convitiatorem \& Calumniatorem longe impudentiffimum, super noviffimis ipfius friptis (Londini Scanorum, 1678); Specimen controversiarum circa jus naturale ipsi nuper motarum (Osnabrugi, 1678); Spicilegium controversiarum, circa jus naturae ipsi motarum (Francofurti, 1680); Dissertio epistolica super controversiis, quae Samueli Pufendorfio cum quibusdam aliis circa jus Naturale intercesferunt (Hamburgi, 1684); Commentatio super invenusto Veneris Lipsicae pullo Valentini Alberti (Frankfurt am Main, 1688); SCHWARTZII, Josuae, Disertatio espitolica ad eximium unum juvencum Severinum Wildschyssium privignum suum (Hamburgo, 1688).

${ }_{35}$ Tal índex redactado por Beckmann y citado a continuación está contenido en la Apología de Pufendorf del año 1674. Pufendorf, Samuel, Apologia pro se et suo libro, Adverfus Autorem Libelli Famosi, cui titulus, Index quarundam Novitatum, quas Dn. Samuel Pufendorf libro suo de Jure Natura \& Gentium contra orthodoxa fundamenta Londini edidit (Leipzig, 1674, Reimp. Frankfurt am Main, Sumtibus Friderici Knochii, 1708), p. 60.

36 Ibíd., p. 60: "Negat Deum naturae suae legibus teneri, ut hoc vel illud agere non possit; affirmatque omnia illa, quae non agere posse dicitur, ex placito non agere, legemque sibi ipsi non nisi ex placito esse".

37 Ibíd., p. 61: “Adeoque legibus obeditur, non principaliter propter rem ipsam, sed propter voluntatem praecipientis”.

38 Ibíd.,: "Quod homo prout ex creatione physice perfectus extitit, sine ordine \& decore, reluctantem habuerit voluntatem, brutisque ipsis pravior fuerit, quae causa, quare lex illi superaddita sit." 
encuentran en naturalem rectitudinem o el entendimiento humano es de modo natural rectum.

Pufendorf cae en el mismo error de Descartes, el hombre estaría gobernado por impulsos y afectos (passiones).

(De lege Natura) El principium cognoscendi del derecho natural es socialitas ${ }^{39}$.

Iustitia Dei no representa el fundamento del derecho natural y por tanto la lex naturae no sería aeterna. Pufendorf sostiene en consecuencia que la lex naturalis sería cambiante según su teoría de los entia moralia.

Pufendorf enseña que los fundamentos de la Ley Natural es la sociabilidad o la naturaleza, en la medida que ella haya sido creada como social por Dios ${ }^{40}$.

(De Magistratu Politico) La soberanía de la autoridad política se erige a partir de contratos entre los súbditos sin la constatación de $\operatorname{Dios}^{41}$.

(De Ministerio Ecclesiastico) El ministro para asuntos eclesiástico no está sometido al derecho del magistrado político ${ }^{42}$.

El punto 1) de nuestra lista es ya una clara muestra de la condena a la idea contractual de formación del Estado, crítica que como veremos se repetirá durante todo el siglo XVIII. Volvamos primero a la reconstrucción del proceso de censura del texto en cuestión. Beckmann, profesor de derecho en Lund y seguramente el más renombrado rival de Pufendorf en este conflicto, intentó a toda costa evitar la publicación de De Iure naturae et gentium, pero fue denunciado y condenado por las autoridades suecas cuando intentó ingresar el Index contra De Iure naturae en las ciudades de Estocolmo, Hamburgo, Gießen y Holms ${ }^{43}$. Beckmann inició una decidida campaña de desprestigio contra Pufendorf en el imperio alemán la cual encontró algunos adherentes ${ }^{44}$. El jurista sajón exigió la salida y proscripción de Beckman al Konsistorium de las autoridades universitarias de Lund en una protesta

39 Ibíd., p. 62: “Genuinum, sufficiens \& adequatum principium cognoscendi legem Naturae esse socialitatem".

40 Ibíd.,: "Principium essendi vel fundamentum Legis Naturae socialitatem esse docet, vel Naturam, quatenus a Creatore socialis facta est".

41 Ibíd., p. 63: "Imperium Magistratus in subditos ex pactis, Deumque causam faltem adprobante".

42 Ibíd.,: "Si minister suo iure, seorsim sibi competente, h.e. ita ut hoc ius non dependeat a magistratu, agat, dominium mundanum contra magistratum sibi sumere".

43 El profesor luterano relata al el Konsistorium de la Universidad de Lund en carta de 4.2.1673. PufEndorf, Samuel, Briefwechsel, cit. (n. 20), p. 92: "Wiewohl gnugsam bewusst, welcher maßen in Göttlichen, natürlichen und aller Völcker rechte, auch absonderlich in denen löblichen gesetzen und placaten dieses Königsreichs unter höchster straffe verboten, dass niemand sich soll gelüsten lassen eines andern guten nahmen und loymund durch pasquillen und schmeheschrifften anzugreiffen und zuverunglimpfen; so hat dennoch dessen alles ungeachtet Dr. Nicolaus Beckamnn Professor Juris Romani Honorarius alhier sich nicht gescheuet im nechstverwichenen jahr ein schendlich ehrenrühig pasquill zu Gießen vermittelst einen dazu von ihm persuadierten Büchhandler in öffentlichen druck ausgehen, und auf der franfurter fastenmasse durch Teutschland und die benachbarten reiche und republicquem distribuiren zulassen".

44 WIESAND, Georg, cit. (n. 5), p. 44. 
de 2.3.1674 ${ }^{45}$. En este contexto, el canciller sueco Gustav Otto von Steinbock ${ }^{46}$ abrió un proceso en contra el autor del Index según la legislación universitaria, de modo que Beckmann en 1674 fue finalmente despojado de su cargo y dignidades ${ }^{47}$. Aunque Beckmann representó la perspectiva tradicional de los teólogos luteranos en este conflicto, Pufendorf contaba con importantes contactos políticos en la corte de Lund, los cuales le permitieron imprimir tanto De Iure naturae 1672, así como el resumen de esta obra, el compendio De Oficcio hominis de 1673. No se puede desconocer que después de dejar su cátedra de Derecho Natural y Gentes en la Universidad de Heidelberg en 1667, Pufendorf ejerció esta misma disciplina en la Universidad de Lund por casi diez años $(1667-1676)^{48}$, para luego ser llamado por el rey sueco Karl XI como historiógrafo de la corte y secretario de Estado hasta 1688, cuando también ocupó una plaza en el consejo secreto de la poderosa monarquía sueca ${ }^{49}$. No es de extrañar entonces que Pufendorf haya podido gozar de los privilegios reales para impresión y edición de sus obras principales.

Es en este sentido para destacar que las autoridades políticas suecas poseían los derechos de publicación y censura de libros, decidían por tanto si una obra, incluso si tratase de teología moral, podía ser impresa, distribuida y publicada en su territorio. Pufendorf conocía bien la legislación de la monarquía sueca en este ámbito, de tal modo que en su Apologie siempre se apoyó en la normativa legal existente $^{50}$. Esto denota bien el fenómeno de la construcción de la normatividad del llamado Estado Moderno en Europa y la realización de los derechos de la

45 PufEndorf, Samuel, Briefwechsel, cit. (n. 20), p. 96: "Gleich wie ich nun in dieser sache nichts anders praetendire, als was dem rechten gemeß, also trage zu E. Hochgräfl. Excell.die unterthänige zuversicht, Sie werden nicht zulaßen, daß Dr. Beckmann, der zumahl seine that zu excusiren nicht gedencket, keine dilation außer was gemeine gesetze und praxis mit sich bringen, indulgieren werde. Weil gnugsam handreiftlich ist, daß der H. Bischof nur suche hiermit zeit zugewinnen, ob etwas mitler weile ein weg außzufinden sey, seinen vertrauten freund von der gebührenden straffe zu entziehen, und meine satisfaction zu eludiren".

46 Incluso Pufendorf dedica al canciller su compendio De officio hominis de 1673.

47 Citado por Palladini, Fiammenta, Einleitung, en Pufendorf, Samuel, Briefwechsel, cit. (n. 20), p. 97: “unter Berufung aufKap. 28, \$ 20 der Konstitution der Universität zu Verlust aller seiner Würden und seiner Ehre verurteilt wurde (Relegatio in perpetuum cum infamia)".

48 NiLSÉN, Peter, Der Staatsrechtsunterricht an den schwedischen Universitäten 1723-1772 en Ius commune 28 (2001), pp. 233-268.

49 Prueba de ello son las obras historicas dedicadas al mandato del rey Karl Gustav. PufENDORF, Samuel, De rebus a Carolo Gustavo Sueciae rege gestis commentarii (s.1. 1696); PUFENDORF, Samuel, Sieben Bücher von denen Thaten Carl Gustavs Königs in Schweden: Mit vortreffichen Kupffern ausgezieret und mit nöthigen Registern versehen (Nürnberg, 1697). Sobre el absolutismo sueco: Mousnier, Roland, La Monarquía Absoluta en Europa, (Trad. Madrid, Taurus, 1986), p. 317; BARUdio, Günter, La Época del Absolutismo y la Ilustración (1648-1779), (1981, Trad. cast. México D.F., Siglo Veintiuno, 1983), p. 26.

50 Pufendorf escribe a Petrus Holm y al Konsistorium de la Universidad Lund en 4.2.1674. PufEndorf, Samuel, Briefwechsel, cit. (n. 20), p. 92: "Consistorij gerichtlichen ausspruch, ob nicht Dr. Beckmann in die straffe verfallen, welche die gesetze und expresse placaten dieses Königsreiches auf sothane ehrenschänder und pasquillanten dictieren; auch mir alle die unkosten und mühe zuerstaten schuldig ist, welche ich bey der witleuftigen inquisition angewendet, und was ferners noch möchte hierinnen anzuwenden seyn. Und solches begehre gebührendt von Consistorio für die injurie, so Dr. Beckmann vermittelst das pasquill mir zugefüget hat". 
soberanía sobre un territorio estatal determinado jurídicamente. Como explica F. Palladini, los intentos de censura de entonces podían llevar a sus acusados a la condena de herejía, lo cual naturalmente era castigado con pena de muerte ${ }^{51}$. Es necesario explicar además que la gran oposición luterana a este libro de Pufendorf se entiende porque el poco ortodoxo tratado del jurista alemán, así la mayoría de sus críticos, representaba un peligroso elemento para la formación académica de estudiantes universitarios ${ }^{52}$. La disposición de censura de Dresden del año 1673 en contra De iure naturae et gentium denunciaba claramente que la teoría de Pufendorf se dirigía contra la ortodoxa y la doctrina pública, conduciendo a los estudiantes a graves errores ${ }^{53}$. Las facultades de teología, derecho y filosofía debían alejar por tanto a sus alumnos de las malas consecuencias de estas opiniones ${ }^{54}$. Este fenómeno es interesante porque la obra De Iure Naturae y su compendio De officio hominis 1673, muy censurados en el siglo XVII, durante el siglo XVIII experimentaron una enorme discusión universitaria y aparecen como parte fundamental de la literatura académica jurídica tanto en territorios católicos como protestantes ${ }^{55}$. La censura de libros tanto por autoridades universitarias como políticas aparece además como un fenómeno comprensible en época de temprana Ilustración, sobre todo tomando en cuenta el amplio dominio de la escolástica, el aristotelismo y la herencia del derecho romano en el sistema educacional europeo ${ }^{56}$. La reconstrucción del

51 Palladini, Fiammetta, Schmidt-Biggemann, Wilhelm, Einleitung en Pufendorf, Samuel, Eris Scandica und andere polemische Schriften über das Naturrecht. Gesammelte Werke 5 (Frankfurt am Main 1686, Berlin, Akademie Verlag, 2002), p. X.

52 Döring, Detlef, Pufendorf in der Welt, cit. (n. 13), p.110: "Tatsächlich wird in jenem 'Rescriptum' des Kurfürsten unter direkter Berufung auf den Index behauptet, dass in de jure 'neuerliche Opiniones' enthalten seien, 'die contra orthodoxiam et receptam Doctrinam publicam lauffen, und bey der Studierenden Jugend großärgerniss und Verleitung zum Irthumb un bösen geben'”.

53 LÜCK, Heiner, Naturrecht in Wittenberg um 1800, en EISFELD, Martin Otto, PAHLOW, Louis, Zwanzger Michael, Naturrecht und Staat in der Neuzeit Diethelm Klippel zum 70. Geburtstag (Tübingen, Mohr Siebeck, 2013), p. 134; LudovicI, Jacob Friedrich, Delineatio Historiae Iuris Divini Naturalis Et Positivi Universalis : Ubi Varia utriusque huius iuris, in specie vero naturalis fata \& dissensiones $D D$. tam veterum, quam recentiorum, circa propositionem praecipue fundamentalem iuris naturae \& conclusiones exinde profluentes historice recensentur (Halle, Renger, 1701), p. 34.

54 Ibíd.

${ }^{55}$ Hammerstein, Notker, Handbuch der deutschen Bildungsgeschichte. 18. Jahrhundert: vom späten 17.Jahrhundert bis zur Neuordnung Deutschlands um 1800 (München, Beck, 2005), p. 377: "Insofern behielten diese Materien anders als im protestantischen Reich großes Gewicht. Das Naturrecht war häufig-und vor dem jus publicum-Anlass für Reformen, und folgerichtig blieben Pufendorf 'De Officio' und Christian Wolfs Arbeiten insgesamt wichtige Grundlangwerke".

${ }^{56}$ El jurista catolico Ludovici cita el Reskript enviado a la Universidad de Leipzig contra De iure naturae gentium (Dresden 1673). LudovicI, Jacob Friedrich, cit. (n. 53), p. 34: “Uns hat die Theologische Facultät aus unserer Universität zu Leipzig unlängst einen so genandten Indicem Novitatum, welchen ein Anonymus aus Samuel Pufendorffs Tractat de jure N.\&G. extrahiret/ unterthänigst eingeschicket/ darinnen allerhand neuerliche Dinge die contra orthodoxiam \& receptam doctrinam publicam laussen und der studierenden Jugend Aergerniß geben/ enthalten sein sollen. Wann wir denn solchem gerne praecaviren möchten/ als begehren wir himit gnädigst/ Ihr wollet denen 3. Facultäten bei euch/ der Theologischen, Juristischen und Philosophischen/ daßSie nach jedes seiner Profession in ihren Lectionibus bei Gelegenheit die studierende Jugend von dergleichen neuerlichen und zu böser Consequentz dienlichen Opinionen alles Fleißes abmahnen sollen/gebührend andeuten". 
contexto en el que aparece el texto de Pufendorf es entonces fundamental según nuestro entendimiento para dimensionar el cambio de significado de esta obra entre un siglo y otro ${ }^{57}$, pero sobre todo permite enriquecer la historia intelectual del concepto de Estado, a través del estudio del entramado histórico cultural y las dinámicas de comunicación jurídica por las que transitaron nuevas concepciones científicas sobre el derecho en una Europa moderna entendida como espacio común de transferencia y comunicación ${ }^{58}$.

\section{CENSURA AL CONCEPTO PUFENDOREANO DE ESTADO}

Una segunda censura experimentada por la obra de Pufendorf es la conocida Epistola censoria de Leibniz al compendio De officio hominis ${ }^{59}$. Lo interesante de esta carta estaba en que apareció como anexo en distintas ediciones y traducciones del texto de Pufendorf durante el siglo XVIII. El editor y erudito alemán Immanuel Weber preparó la edición de 1709 en Frankfurt am Main, la cual incluía en el apéndice justamente las Castigationes de Leibniz hechas al texto de Pufendorf, de tal manera que las tesis de ambos pensadores alemanes circularon juntas en plena Ilustración europea. Con ello tenía a disposición el público lector ilustrado un amplio panorama sobre las distintas maneras de interpretación en esta disciplina. Leibniz discutía en su carta de censura que Pufendorf no había considerado los temas de la inmortalidad del alma, la justicia o condena divina y la recompensa superior de Dios como instancias normativas del ius naturae, de tal modo que se había contentado con un grado inferior de entendimiento del derecho natural ${ }^{60}$. Con esta delimitación había Pufendorf ignorado intencionalmente las importantes contribuciones metafísicas de los iusnaturalistas antiguos, griegos, romanos y cristianos, reduciendo la normatividad del derecho natural a los límites e intereses de esta vida (dieseitiges Lebens) ${ }^{61}$. Leibniz reconocía en cambio como autoridades a Aristóteles, la Escolástica y la metafísica, fuentes intelectuales despreciadas por el jurista sajón. Por esta razón, Pufendorf como Thomasius son

57 SkInner, Quentin, Visions of Politics, Vol III, Hobbes and Civil Science (Cambridge, Cambridge University Press, 2005), p. viii.

58 Wunderer, Hartman, Staat und Herrschaft in der Frühen Neuzeit (Stuttgart, Reclam, 2014), p. 95; DuchHardt, Heinz/ SCHnetTGer, Matias, Barock und Aufklärung ${ }^{5}$ (Göttingen, Oldenburg, 2015), pp. 199-201.

59 LeIBNIZ, Gottfried Wilhelm, Epistola censoria qua principia illustris Pufendorfii in libello de officio hominis et civis adhibita, obelo notate voluit; cum Monitis apolgeticis Immanuelis Weberi. Thematum quorundam selectiorum, Ex Ilustris Pufendorfii de Officiis Libello Excerptorum, et Publicis Disputationibus in Academia Giessens (Frankfurt am Main, reimp. 1719).

${ }^{60}$ LEIBNIZ, Gottfried Wilhelm, Algunas observaciones sobre las ideas fundamentales de Samuel Pufendorf, dirigidas a G. W. Molano, en ÉL MISMO, Escritos de Filosofia Jurídica y Política (1719, trad. cast. Madrid, 2001), p. 168: "Por ello, olvidar aqui esta preocupación por la vida futura, que está inseparablemente unida a la providencia divina, y quedarse satisfecho con un grado inferior del derecho natural, que incluso puede ser válido a los ojos de un ateo (de ello ya he hablado en otra parte) es privar a esta disciplina de una parte muy hermosa $y$, además, suprimir muchos deberes que deben cumplirse en esta vida”.

61 Ibíd. p. 169. 
a la vista de Leibniz pensadores superficiales y sin tradición ${ }^{62}$, que abarcaban una serie de temas sin profundidad y cuyo éxito se debía más bien a una a amplía red de contactos de poderosos políticos como la Monarquía sueca ${ }^{63}$. Döring explica que los permanentes ataques de Leibniz a Pufendorf, se explican solamente a través de la sicología (tiefe Feindschaft). Mientras Leibniz no alcanzó a ser ni bestseller ni disfrutó de importantes dignidades nobiliarias en los grandes centros cortesanos de Europa, gozó Pufendorf en vida de un gran reconocimiento intelectual, social y sobre todo político, lo cual para Leibniz habría sido fundamental para la producción literaria del jurista sajón ${ }^{64}$.

En su edición de De officio hominis de 1709 agrega Weber además dos disputas públicas sobre el libelo de Pufendorf entre el profesor de matemáticas oriundo de Leipzig Joh. Friedrich Känser y su contrincante Alberto Hartman. Para Käsner ya es claro en 1709 que el debate sobre los fundamentos de ius naturae se realizaba entre escolásticos y los seguidores de Pufendorf. Käsner nos entrega una positiva opinión de las nuevas tendencias científicas y es crítico de los escolásticos, los cuales cataloga de ignorantes, porque no habían investigado correctamente el derecho natural y solamente habrían formulado prejuicios en contra de Pufendorf ${ }^{65}$. Los disputantes explican además que la utilización del derecho natural para intereses propios (particularis) propuesto por Pufendorf fue criticado por los juristas ortodoxos, los cuales defendían el carácter de universalis del ius naturalis. Un ius naturae en conexión con universalibus depende de voluntas $d e i^{66}$, por el contrario depende un derecho natural particularis de la voluntad del legislador ${ }^{67}$. De ello resulta una importante consecuencia según Känsers: ius naturae en el pensamiento de Pufendorf se ocupa exclusivamente con ratio, no con teología moral ${ }^{68}$. Este es un gran giro de significado en la teoría de Pufendorf advertido por Känser, el objetivo del derecho natural para el jurista sajón sería la felicidad terrenal de la sociedad civil. Comenta Käsner que esta delimitación de la normatividad del derecho natural a la regulación de esta vida y su renuncia a un derecho natural en conexión con el orden divino, hacían que iure naturae se dirigiese a regular lo

${ }^{62}$ Doring, Detlef, Pufendorf in der Welt, cit. (n. 13), p. 314: "Leibniz hat seinen Landsmann als einen Gelehrten betrachtet, dessen geistiges Niveau sich nicht im geringsten mit seiner, Leibniz ' wissenschaftlichen Bedeutung als eines alle Tiefen des Seins auslotenden Philosophen vergleichen läßt”.

63 Ibíd.: "In Leibniz 'Augen bewegen sich Zeitgenossen wie Pufendorf und Thomasius in einer Welt, die nicht die seinige ist. Mit ihnen kann es keine Auseinandersetzungen geben, die aufgleicher Ebene angesiedelt sind".

${ }^{64}$ Welzel, Hans, Die Naturrechtslehre Samuel Pufendorfs : e. Beitr. zur Ideengeschichte d. 17. u. 18. Jh. (Berlin, 1958), pp. 4-6.

${ }^{65}$ KäNSER Joh. Friedrich, Disertaciones Thematum quorundam selectiorum, Ex Ilustris Pufendorfii de Officiis und Libello Excerptorum, et Publicis Disputationibus in Academia Giessens (s.l. 1723), p. 4: "Dissentiunt Scholastici, \& vulgo sic dicti Moralistae omnia sursum deorsum vertentes, \& ex Theologia, Philosophia morali, Jure Naturali \& civili unum aliquod Chas conficientes. Dissentiunt etiam, qui praecepta Decalogica pro ipso Jure Naturae haberi volunt".

66 Ibíd., p. 3.

67 Ibíd. "Forma Legis divinae revelatae consistit in obligatione ad foederis modum contracta; sed Juris Naturae praecepta obligant simpliciter ex Llatoris voluntate".

${ }^{68}$ Ibíd.: "Quia differunt principio cognoscendi, forma, objecto \& sine. Principium cognoscendi Theologiam moralem est Revelatio; Jus Naturae, ratio". 
justus y no lo honestus de las acciones humanas. La filosofía moral se concentraba por el contrario en lo honestus y rectitude interna en actionies humanas, tópicos que no eran tema del derecho para Pufendorf ${ }^{69}$. Känser intenta en consecuencia aclarar que el Naturrecht planteado por Pufendorf, para ser una ciencia verdadera, debía necesariamente ser independiente de la teología. Los escolásticos, como Pufendorf remarcaba, no habían logrado diferenciar entre justus, decorus y honestus así como entre obligatio interna y obligatio externa, dado que para tales doctores justus y honestus representaban la misma cosa. En este sentido, comenta Känser sobre el modum cognoscendi del derecho natural que sus cualidades de abstrahere y praesumere hacían del ius naturae una verdadera ciencia. Llamativo resulta para Känser que la mayoría de los críticos del método científico en su época fuesen justamente aquellos, los cuales rechazaban la abstracción racional del estado de naturaleza del hombre propuesto por el jurista sajón ${ }^{70}$. Los neo escolásticos sostenían, así Känser, que la creación o inventio de una idea del hombre, la cual no tuviese relación con la narrativa y relato de la biblia, representaba directamente una herejía.

En esta disputa contra argumenta el Respondente Jo. Alberto Hartman (HalaSuevo) en el tema XII de la segunda Disputa sobre la causa constituendarum Civitatum propuesta por Pufendorf, que "Status hominum naturalis sic concipiendus est, ut ab eo recta rationis dictamina \& Naturae Jura non excludantur" ${ }^{71}$. Esta concepción se contraponía según la fuente a los que creían que podían encontrarse rectus y justus en la naturaleza humana y que esta característica "ac spontaneitatem in actionibus naturalibus relinquunt"72. Siguiendo la descripción de Hartman, frente a la imagen aristotélica escolástica del hombre, la cual era fuertemente defendida en la filosofía escolar escolástica del siglo XVIII ${ }^{73}$, aparecían como contraparte las tesis de Hobbes y Spinoza, quienes negaban que el derecho natural representara una moral dada por Dios ${ }^{74}$. Los errores de Hobbes, así el documento, habían sido inadvertidos por Pufendorf cuando el jurista sajón formula su propia teoría del oblitus hominem dominado por el deseo e impulso a la guerra ${ }^{75}$. En el tema XI precisa Hartman el concepto de impulso social del hombre, cuyos representantes

69 Ibíd., p. 2.

70 Ibíd., p. 5: „Dissentiunt, qui vel ex stupiditate vel malitia peccantes in Pufendorfio hoc ferre no lunt, quod conditionem primi hominis ad captum rationis, non ad ductum verbi revelati formaverit".

71 Hartman, Jo. Alberto, cit. (n. 65), p. 30.

72 Ibíd.

73 Stone, M. F. W., Scholastics Schools and Early Modern Philosophy, en ÉL MISmo, The Cambridge Companion to early modern philosophy (Cambridge, Cambridge University Press, 2006), p. 303: "In the Netherlands, Protestant scholastics were among the very first to engage systematically with the new approach to philosophy and science of Descartes, while in German-speaking countries a tradition of scholastic metaphysics remained influential even as late as the last decades of the eighteenth century and was closely associated with the work of Christian Wolff(1679-1754)".

${ }^{74}$ Hartman, Jo. Alberto, cit. (n. 65), p. 31: "Pejor tamen Spinosa Hobbesio, quod a suo statu per dictamina rationis hic hominem abducendum, sicque eum corrigendum docet; ille vero ipsam sui status qualitatem hanc pro Principio Juris Naturalis habet, \& retinendam inculcat, fic ut ex ejus mente, quosque hominis libido ac potentia, eousque etiam ejusdem Jura sese extendant".

75 Ibíd.: "Ab errore Hobesiano non fatis sibi cavit ipse noster Author, dum sui oblitus hominem in stat. Nat. imperio affectuum subjicit, bellumque ei proprium facit”. 
en su época eran Boecler, Hornius, Zegler y Grotius ${ }^{76}$. Los seguidores de esta teoría pensaban según Hartman que las mismas primeras cabezas de familia -patres familia y seniories- ejercían autoritas y majestas en el estado natural y más tarde poseían también en la sociedad civil la llamada civili autoritas ${ }^{77}$. Contradiciendo a Pufendorf, Hartman marcaba en estos pasajes la conocida analogía " imperium familiare cum Civili, \& potestas Majestati analoga cum Majestate proprie “78. El concepto de Estado que acá se infiere puede ser expresado como una evolución o proyección del gobierno natural de los pater o seniores sobre familias. Es decir, el proceso de formación del Estado sería más bien una evolución autónoma del orden natural deseado por la voluntad de Dios, en el cual los hombres no tienen ninguna participación en la configuración contractual del poder y la autoridad como pretendía Pufendorf $^{79}$. El grupo de autores Conring, Pufendorf, Thomasius y Hertius, comenta el disputante, planteaban en cambio que el Estado no podía ser interpretado como la continuidad de la libertad natural en el estado de naturaleza ${ }^{80}$. Hartman sostiene en este sentido, en relación a la causa para la erección del Estado y la soberania (causa efficiente civitatis \& imperii civilis), que la causa majestatius aparece como una obra de Dios, sin embargo no de una manera directa ${ }^{81}$. Conciliando con Pufendorf, plantea Hartmann que el Estado desde tiempos inmemoriales fue concebido como un acto de Dios (summa imperia sunt ex ordinatione divina) $)^{82}$, pero en su época se había llegado al convencimiento de que este era más bien un complexus jurium, en el cual los súbditos tienen la posibilidad de traspasar la soberanía (summum imperantem) a través de pactos $^{83}$. Hartman agrega que tal tesis sería compartida por Petrum, Scherzer, Grotius, Pufendorf, Thomasius y Hertius entre otros juristas. Mientras que los críticos de esta teoría serían principalmente los teólogos que defendían la formulación bíblica de Paulo en Romanos XIII, I ${ }^{84}$. En el tema XVIII se establece en el escrito de Hartman que summa imperia solamente pueden ser legítimos a través de contratos y convenios de los hombres. En este sentido, son rechazadas por Hartman la guerra y la herencia como medios para crear un Estado ${ }^{85}$. Hobbes en De Cive

76 Ibíd., p. 43: “ergo natum esse hominem quemvis, \& destinatum ad societatem civilem, tanquam omnium perfectissimam".

77 Ibíd., p. 45.

78 Ibíd.

79 Ibíd., p. 46.

${ }^{80}$ Ibíd., p. 43: "Ratio, quia posita socialitate in homine degente in statu naturali, sequitur, ad eas tantum societates eum ferri ordinarie, quae statui naturali sunt convenientes. Imperium Civile libertati naturali adversum est. Officia ex Civitatum instituto orta saepe cum philautia hominis naturali colliduntur”.

${ }^{81}$ Ibíd. p. 46: "Deus est causa Majestatius, sed hodie non inmediata".

82 Ibíd.

${ }^{83}$ Ibíd. : "Ratio, quia Majestas est complexus jurium atque facultatum à subditis in Summum Imperantem per conspirationem translatarum. Deus immediate Reges \& Principes hodie non constituit , sed mediantibus pactis \& conventionibus hominum existent".

84 Ibíd., p. 47: "Ratio, quia esta aliquod totum, \& per partes seu distinctos actus sese exserit. Quia si plures divisim \& independenter jura Majestatis in Republica possiderent, sequeretur, dari uno pluro summa capita in Republica, quod absurdum".

${ }_{85}$ Ibíd., p. 52: "Ratio, quia quocunque modo habeat Imperans jus in civitatem, sive per oc- 
y Leviathan es para el disputante el principal crítico de esta concepción, la cual también es apuntada por Pufendorf en Lib. Vii. c. $2^{86}$. Sin consensio no puede erigirse civitas ni summa potesta. En el cap. V causa civis constituenda de Pufendorf se trataban justamente las dos opciones de un contrato de formación del Estado. Hartman explica finalmente que o los ciudadanos transferían la completa summa imperium al Estado (civitas) o mantenían ellos una parte, la cual podía ser ejercida como derechos fundamentales (Derecho de resistencia) ${ }^{87}$.

\section{UN EJEMPLO DE CENSURA CATÓLICA}

La censura al texto de Pufendorf De iure naturae et gentium 1672 fue emprendida también en el ámbito católico, precisamente en la accommodatio del jurista austriaco y filósofo del derecho Karl von Martini, la cual aparece en su conocido Leitstaatsrechtslehrbuch de $1781^{88}$. Martini confrontó la teoría contractual de formación del Estado de Pufendorf en la cultura jurídica católica en el siglo XVIII tal como lo hicieron Juan Bautista Almicci y Francesco Finneti en Italia, o en España el ilustrado valenciano Gregorio Mayans y Siscar ${ }^{89}$. Interesante, como veremos, son los puntos en común entre los procesos de censura. A pesar de la barrera confesional y las transformaciones histórico-culturales de casi un siglo, aparecen claras concomitancias entre el mundo intelectual protestante y católico, lo que da constancia de los procesos de comunicación jurídica regional transnacionales y las dinámicas de intercambio y transferencia de conocimiento jurídico en el mundo moderno. Tales interacciones científicas fueron a nuestro entender claves para el desarrollo de la teoría del Estado en época de la Ilustración. Sobre el tema de la formación del Estado en el tratado de Pufendorf, sostiene el jurista austriaco que la interna constitución del Estado estaba realmente en la unión de las voluntades y fuerzas de los padres de familia (Familienhäupter $)^{90}$. Aunque para Martini el

cupationem bellicam, sive per electionem, sive etiam per haereditatem, nullo tamen horum securus esse potest, nisi fide \& voluntate subditorum nitatu, quod etiam exinde patet, quia semper homagia à subditis exiguntur".

${ }^{86}$ Ibíd: "Dissentiunt Hobbes, qui generaliter negat, pactum aliquod imperantes inter \& subditos intercedere, \& quidem ex vano metu, ne ut, obligatio ex pactis reciproca est, sic etiam jus aequale utrinque nascatur".

87 Ibíd., p. 51.

88 MarTini, Carl Anton von, Lehrbegriff des Natur-, Staats- und Völkerrechts (1783-84, trad. alem. Aalen, 1969).

89 Almici, Juan Bautista, Institutiones Iuris Naturae, Et Gentium Secundum Catholica Principia (Brescia, 1768); Pufendorf, Samuel von, Almici, Juan Bautista, Il diritto della natura e delle gentiosia sistema generale de' principii li piu' importanti di morale, giurisprudenza e politica (1672, Trad. ital. Venecia, Valvasene, 1757); FINETTI, Giovanni Francesco, De principiis iuris naturae et gentium adversus Hobbesium, Pufendorfium, Thomasium, Wolfium, et alios (Venecia, 1764); MaYANS y SisCar, Gregorio, Filosofía Cristiana apuntes para ella (Valencia, 1747). En el ambito alemán se encuentran entre otras: DESING, Anselm, Iuris naturae larva detracta compluribus libris sub titulo iuris naturae prodeuntibus, ut Pufendorfianis, Heineccianis, Wolffianis et aliis (Monachi, 1753); SCHWARZ Ignacio, Institutiones juris publici universalis, naturae, et gentium, ad normam moralistarum nostri temporis, maxime protestantium, Hugonis Grotii, Pufendorfii (Agustae, 1743).

90 Martini, Carl Anton von, cit. (n. 88), p. 19. 
principal objetivo de esta unión también era la defensio communis (Sicherheit), ocupa el jurista austriaco la línea argumentativa de Aristóteles ${ }^{91}$. Martini reconoce la enorme difusión del modelo contractual de construcción de las estructuras estatales de Pufendorf entre los doctores de su época ${ }^{92}$, sosteniendo sin embargo que el contrato de formación del Estado (Staatsentstehungsvertrag) propuesto por el jurista sajón sería improbable. Los padres de las primeras familias estaban en condiciones, así Martini, de erigir un Estado pero no a consecuencia del cierre de una explicita relación contractual, más bien como consecuencia de una antigua convivencia en común (uralte Beisammenwohnung). Este conjunto humano aparece en Martini como algo casual, natural y espontáneo, dado que los hombres largo tiempo erraron por el mundo antes de que se organizaran en Estados ${ }^{93}$. El relato de los antiguos, pasado de alto por Pufendorf según Martini, confirmaría que este mando superior sería original, constituido a partir del antiguo gobierno de las primeras familias y cuya participación del pueblo estaba dada por contrato tácito. Un pacto expreso entre autoridad y pueblo, como el propuesto por Pufendorf, es entonces innecesario para Martini ${ }^{94}$. El crítico austriaco llega así a la conclusión que el proceso de formación del Estado podía ser aclarado sólo a través de un contrato tácito y este sería suficiente con el primer pacto propuesto por Pufendorf en su teoría ${ }^{95}$. Sospechoso era para el jurista católico que su colega luterano no fijara a lo largo de su extensa obra ninguna forma de gobierno específica como la mejor Regierungsform, sino dejara esta decisión abierta a los asociados quienes lo determinan según un Dekret ${ }^{96}$. Este planteamiento de Pufendorf dejaba abierta

91 Ibíd., p. 27.

${ }^{92}$ Ibíd., p. 20: "Viele sind mit Pufendorfen der Meinung, jeder Staat sie durch zwei Verträge und eine Verordnung zu Stand gekommen. Den ersten und hauptsächlichsten Vertrag hätten nach seinem Dafürhalten einzelne, in der natürlichen Freiheit lebende Menschen mit anderen einzelnen, in gleichem Fall sich befindenden Menschen eingegangen, wie sie nämlich in eine ungetrennte und für dauernde Gesellschaft zusammentreten und für ihre Wohlfahrt und ihre Sicherheit gemeinschaftlich sorgen wollten".

${ }^{93}$ Ibíd., p. 21: “Allein, wie könnten Hausväter je unter sich eins werden, einen Staat errichten zu wollen, wenn sie nicht zuvor schon ziemlich nahe beisammen wohnten. Diese Beisammenwohnung kam doch gewiss von keinem Vertrage, sondern vielmehr daher, daß die Menschen entweder erst einzeln auf der Welt herumirrten und denn nach langer Zeit in gewissen Gegenden ungefähr zusammen trafen, oder, daß sie von irgend einem gemeinschaftlichen Vater abstammend, sich von jeder auf nachbarlichen Fluren aufhielten".

${ }^{94}$ Ibíd., p. 24: "Es ist übrigens leicht zu sehen, daß es eben nicht notwendig ist, daßso ein Vertrag mit ausdrücklichen Worten geschlossen werde. Genug, wenn das Volk stillschweigend darüber enig wird, welches damals geschehen zu geschehen scheint, wann über die Mittel, die gemeinschaftliche Sicherheit zu erhalten, nach Maaß der eingeführten Gewohnheit zu Rath gegangen, und bei sich dußernden Fällen sogar wechselweiser Beidtand geleitet wird".

${ }^{95}$ Ibíd.: "Es ist also deutlich, daß zu dem Wesen eines Staats überhaupt ein einziger Vertrag zureichend ist, ein solcher nämlich, durch welchen alle Einzelnen ihren Willen dem Willen aller insgesamt unterwerfen. Dieser Vertrag mag nun der Vertrag der Unterwerfung oder der bürgerlichen Vereinigung genennt werden, das gilt gleich".

${ }^{6}$ Ibíd., p. 20: "Dieser Verordnung beizufallen, sein zwar diejenigen nicht schuldig, die sich im ersten Vertrage eine, von der nun eingeführten unterschiedene Regierungsform ausgedingt hätten: Alle übrigen aber, seien dergestalt daran gebunden, daß sie den Stimmen der mehreren sich nothwendig fügen müßten". 
más bien la posibilidad de una forma de gobierno distinta a la monarquía, lo que naturalmente es criticado por Martini. El centro de la argumentación de Pufendorf para la formación del Estado descansaría según el jurista católico en el primer pactum, a través del cual cada uno somete su voluntad a la voluntad de todos los otros o a una gran parte de los asociados. Con este proceso estamos según Martini ya en presencia de un Estado, de manera que la figura de un decreto y un segundo pacto planteado por Pufendorf serían innecesarios ${ }^{97}$. El proceso de sometimiento de todos a un mismo gobierno general (Herrschaft), así como la decisión sobre la mejor forma de gobierno debía según el crítico católico ser efectuadas por simples acuerdos y su mejor expresión era la monarquía ${ }^{98}$.

\section{ConClusión}

Como hemos planteado, el objetivo de este artículo fue reconstruir los procesos de censura experimentados por el principal tratado de Samuel Pufendorf De iure naturae et gentium (Lund, 1672) y del compendio De officio hominis et civis (Lund, 1673), deteniéndonos principalmente en el concepto de Estado allí planteado. En este sentido, es para concluir que la propuesta contractual de formación del Estado territorial soberano de Pufendorf, aunque no representa una originalidad del jurista sajón, fue discutida y reformulada desde fines del siglo XVII hasta fin de siglo XVIII tanto en la cultura jurídica católica como protestante. Solamente hemos tomado tres casos relativos al ámbito intelectual comprendido por el Sacro Imperio Romano de la Nación Alemana, sin embargo la teoría jurídica de Pufendorf alcanzó un carácter internacional y su influencia ha podido ser probada en espacios de difusión extremos como la monarquía rusa o al otro lado del Atlántico. No hemos querido en este artículo enfocarnos meramente en una historia intelectual del concepto de Estado en Pufendorf buscando su contribución a la cultura política contemporánea y la modernidad política jurídico, este intento ha sido logrado por excelentes monografías ya citadas, más bien apuntamos a los procesos de comunicación jurídica entre culturas intelectuales opuestas marcadas por los coletazos de la confesionalización de Europa (reforma/contrarreforma) así como de la traumática Guerra de los Treinta Años (1618-1648). La exitosa comunicación de la idea de Estado Moderno de Pufendorf en el espacio jurídico común europeo lleva consigo una larga historia social cultural más compleja, la cual es posible de conocer gracias a la historia de las censuras inquisitorial de libros, la reconstrucción de redes de impresión y reedición de textos, así como del entramado político ideológico que sirvió de contexto histórico para la aparición de una obra como De iure naturae et gentium. Finalmente es de destacar que los procesos de circulación de saberes, ideas y textos normativos sobre la formación del Estado territorial moderno, entre otros temas que componían el ius publicum

${ }^{97}$ Ibíd., p. 22: "Wenn also nach Pufendorfs Dafür halten dieser Zustand sogleich auf den ersten Vertrag folgt, so ist offenbar, daß der zweite Vertrag und die dazwischen aufzurichtende Verordnung überhaupt überflüßig sind".

${ }^{98}$ Ibíd.: "Aber wann wird diese Handlung nicht mehr zu den Verträgen, sondern zu den bloßen Abreden müssen gezählt werden”. 
europeaum, son fuentes históricas de enorme relevancia para entender las interacciones científicas y los intercambios culturales en el mundo moderno. Tales debates y polémicas transconfesionales y transnacionales fueron lógicamente fundamentales para comprender el proceso de construcción de la normatividad del Estado soberano en época de Ilustración europea y de su vocabulario político.

\section{BiBLIOGRAFÍA}

AmunÁtegui, Domingo, Los primeros años del Instituto Nacional (1813-1836) (Santiago, Imprenta Cervantes, 1888).

Almici, Juan Bautista, Institutiones Iuris Naturae, Et Gentium Secundum Catholica Principia (Brescia, 1768).

BARUdio, Günter, La Época del Absolutismo y la Ilustración (1648-1779), (1981, Trad. cast. Mexico D.F., Siglo Veintiuno, 1983).

BeHme, Thomas, Samuel von Pufendorf: Naturrecht und Staat. Eine Analyse und Interpretation seiner Theorie, ihrer Grundlagen und Probleme (Göttingen, Vandenhoeck \& Ruprecht, 1995).

BÖCKENFÖRDE, Ernst-Wolfgang, Geschichte der Rechts- und Staatsphilosophie, Antike und Mittelalter (Tübingen, UTB, 2002).

Bornstein, Félix, José Rodríguez Campomanes. Los límites del reformismo ilustrado, en Revista de Estudios Politicos (Nueva Época) 118 (2002).

DeFourneaux, Marcelin, Linquisition espagnole et les livres français au XVIIIème siècle (París, 1963).

DesING, Anselm, Iuris naturae larva detracta compluribus libris sub titulo iuris naturae prodeuntibus, ut Pufendorffianis, Heineccianis, Wolffianis et aliis (Monachi, 1753).

DörIng, Detlef, Pufendorf in der Welt des 17. Jahrhunderts. Untersuchungen zur Biographie Pufendorfs und zu seinem Wirken als Politiker und Theologe (Frankfurt am Main, Vittorio Klostermann, 2012).

DöRING, Detlef, Samuel Pufendorf und die Leipziger Gelehrtengesellschaften in der Mitte des 17. Jahrhunderts (Berlin, 1989).

Duchhardt, Heinz/ SchnetTger, Matias, Barock und Aufklärung (Göttingen, Oldenburg, 2015).

Fernández Sarasola, Ignacio, La dimensión política de Jovellanos, en Juan Velarde, Jovellanos: el hombre que soñó España, (Madrid, Encuentro, 2012).

FinetTI, Giovanni Francesco, De principiis iuris naturae et gentium adversus Hobbesium, Pufendorfium, Thomasium, Wolfium, et alios (Venecia, 1764).

Fiorillo, Vanda/ GrunerT, Frank, Das Naturrecht der Geselligkeit: Anthropologie, Recht und Politik im 18. Jahrhundert (Berlin, Duncker \& Humblot, 2009).

Gajardo Villarroel, Enrique, Reseña histórica de la enseñanza superior en Chile y del estudio del derecho de gentes, antes y después de la independencia (Santiago de Chile, Taller Imprenta, 1928).

Glafey, Adam Friedrich, Vollständigen Geschichte des Rechts der Vernunft (Leipzig, 1739).

HaAs, Julia, Die Reichstheorie in Pufendorfs "Severinus de Monzambano" Monstrositätsthese und Rechtsdebatte im Spiegel der politisch-juristischen Literatur von 1667 bis heute (Berlin, Duncker \& Humbolt, 2007).

Hammerstein, Notker, Handbuch der deutschen Bildungsgeschichte. 18. Jahrhundert: 
vom späten 17.Jahrhundert bis zur Neuordnung Deutschlands um 1800 (München, Beck, 2005).

Huesbe, Marco, La teoría política de Samuel Pufendorf a través de su comentario a la constitución del imperio romano-germánico (1667), en Revista de Estudios HistóricoJurídicos 31 (2009).

HüNING, Dieter, Naturrecht und Staatstheorie bei Samuel Pufendorf (Baden-Baden, Nomos, 2009).

Hunter, Ian, Saunders, David, Introduction, en Pufendorf, Samuel, The whole duty of man according to the law of nature (London 1691, trad. ingl. Indianapolis, Liberty Fund, 2003).

Kaltenborn, Carl von, Die Vorläufer des Hugo Grotius auf dem Gebiete des Jus naturae et gentium (Leipzig, Verlag von Gustav Mayer, 1848).

KÄNSER, Joh. Friedrich, Thematum quorundam selectiorum, Ex Ilustris Pufendorfii de Officiis und Libello Excerptorum, et Publicis Disputationibus in Academia Giessens (s.l. 1723).

LeIBNIZ, Gottfried Wilhelm, Epistola censoria qua principia illustris Pufendorfii in libello de officio hominis et civis adhibita, obelo notate voluit; cum Monitis apolgeticis Immanuelis Weberi. Thematum quorundam selectiorum, Ex Ilustris Pufendorfii de Officiis Libello Excerptorum, et Publicis Disputationibus in Academia Giessens (Frankfurt am Main, 1719).

LeIBNIZ, Gottfried Wilhelm, Algunas observaciones sobre las ideas fundamentales de Samuel Pufendorf, dirigidas a G. W. Molano, en ÉL MISMO, Escritos de filosofía jurídica y politica (1719, 2001, trad. cast. Madrid).

Ludovici, Jacob Friedrich, Delineatio Historiae Iuris Divini Naturalis Et Positivi Universalis: Ubi Varia utriusque huius iuris, in specie vero naturalis fata \& dissensiones DD. tam veterum, quam recentiorum, circa propositionem praecipue fundamentalem iuris naturae \& conclusiones exinde profluentes historice recensentur (Halle, Renger, 1701).

LÜCK, Heiner, Naturrecht in Wittenberg um 1800, en EISFELD, Martin Otto, PAHLOW, Louis, ZwanZGer Michael, Naturrecht und Staat in der Neuzeit Diethelm Klippel zum 70. Geburtstag (Tübingen, Mohr Siebeck, 2013).

Martínez Albiach, Alfredo, Grocio-Pufendorfante Mayáns-Campomanes, en Cuadernos de Estudios del Siglo XVIII, CES 6-7 (1996-1997).

MarTINI, Carl Anton von, Lehrbegriff des Natur-, Staats- und Völkerrechts (1783-84, trad. alem. Aalen 1969).

MAYANS y SiSCAR, Gregorio, Filosofia Cristiana apuntes para ella (Valencia, 1747).

Medina, José Toribio, Historia del Tribunal del Santo Oficio de la Inquisición en Chile (Santiago, Fondo Bibliográfico J. T. Medina, 1952).

Monzambano, Severinus, De statu imperii germanici ab Laelium fratem, dominum Trezolani, liber unus (Genf, Den Haag, 1667).

MousNier, Roland, La monarquía absoluta en Europa, (Trad. Madrid, Taurus, 1986)

NILSÉN, Peter, Der Staatsrechtsunterricht an den schwedischen Universitäten 1723-1772 en Ius commune 28 (2001).

Othmer, Sieglinde C., Berlin und die Verbreitung des Naturrechts in Europa: kultur- und sozialgeschichtliche Studien zu Jean Barbeyracs Pufendorf-Übersetzungen und eine Analyse seiner Leserschaft, (Berlin, De Gruyter, 1970).

Palladini, Fiammetta, Schmidt-Biggemann, Wilhelm (eds.), Einleitung en Pufendorf, Samuel, Eris Scandica und andere polemische Schriften über das 
Naturrecht. Gesammelte Werke 5 (Frankfurt am Main 1686, Berlin, Akademie Verlag, 2002).

Pérez Godoy, Fernando, La presencia de las ideas politicas de Samuel Pufendorf durante la independencia de Chile en Revista Derecho y Humanidades 17 (2011).

Pufendorf, Samuel, De rebus a Carolo Gustavo Sueciae rege gestis commentarii (s.l. 1696).

Pufendorf, Samuel von; Almici, Juan Bautista, Il diritto della natura e delle gentiosia sistema generale de principii li piu' importanti di morale, giurisprudenza e politica (1672, Trad. ital. Venecia, Valvasene, 1757).

Pufendorf, Samuel, Sieben Bücher von denen Thaten Carl Gustavs Königs in Schweden: Mit vortrefflichen Kupffern ausgezieret und mit nöthigen Registern versehen (Nürnberg 1697).

PufEndorf, Samuel, De jure naturae et gentium libri octo (Londini Scanorum, Adam Junghans, 1672).

PufEndorf, Samuel, Briefwechsel. Gesammelte Werke, (1673, Berlin, Akademie Verlag, 1996).

Pufendorf, Samuel, De officio hominis et civis juxta legem naturalem. Gesammelte Werke, (Lund 1673, Bd. 2. Reimp. Berlin 1997).

PufENDORF, Samuel, Kurzer, doch gründlicher Bericht von dem Zustande d. H. R. Reichs Teutscher Nation in Lateinischer Sprache unter dem Titel Severin von Monzambano herausgegeben, [Gledirsch, Johann Ludwig; Weidmann, M. W. editores], (1667, trad. alem. Leipzig, 1710).

Pufendorf, Samuel, Apologia pro se et suo libro, Adverfus Autorem Libelli Famosi, cui titulus, Index quarundam Novitatum, quas Dn. Samuel Pufendorf libro suo de Jure Natura \& Gentium contra orthodoxa fundamenta Londini edidit (Leipzig 1674, Remp. Frankfurt am Main, Sumtibus Friderici Knochii, 1708)

Pufendorf, Samuel, Apologie pro se et suo libro, adversus autorem libelli famosi, cui titulus, index quarundam novitatum, quas Dn. Samuel Pufendorf libro suo de iure Natura \& Gentium contra orthodoxa fudamenta Londini edidit. Germanopoli, 1674, Samuelis Pufendorfi Epistola ad... Joh. Adamum Scherzerum, super censura quapiam in librum suum inique lata. (Lund, Hardervici, 1674).

Pufendorf, Samuel, Eris scandica, (Frankfurt am Main, Friedrich Knoch, 1688).

RADKAU, Joachim, Holz - Wie ein Naturstoff Geschichte schreibt (München, Ökom, 2012)

SANTO Oficio de LA INQUisición, Índice General de los libros prohibidos, compuesto del indice último de los libros prohibidos y mandados expurgar hasta fin de diciembre de 1789 por el señor inquisidor general y señores del supremo consejo de la Santa General Inquisición, de los suplementos del mismo, que alcanzan hasta 25 de agosto de 1805, $y$ además de un index librorum prohitorum juxta exemplar romanum jessu ss. $d$. $n$. Editum anno MDCCCXXXV, en el van intercalados en sus respectivos lugares los prohibidos hasta fin de 1842 (Madrid 1844).

SANTO Oficio de la InQUisición EsPañola, Indice de los libros prohibidos por el Santo Oficio de la Inquisición Española, desde su primer decreto hasta el último, que espidio en 29 de mayo de 1819, y por los obispos españoles desde esta fecha hasta fin de diciembre de 1872. [Carbonero y Sol Santo, León editor] (Madrid, Imprenta de D. Antonio Perez Dubruij, 1873).

SCHWARZ Ignacio, Institutiones juris publici universalis, naturae, et gentium, ad normam 
moralistarum nostri temporis, maxime protestantium, Hugonis Grotii, Puffendorfii (Agustae, 1743).

SCHWARTZII, Josuae, Disertatio espitolica ad eximium unum juvencum Severinum Wildschyssium privignum suum (Hamburgo, 1688).

Silva Castro, Raúl, Fundación del Instituto Nacional (1810-1813) (Santiago, 1953).

SkInNer, Quentin, Visions of Politics, Vol III, Hobbes and Civil Science, (Cambridge, Cambridge University Press, 2005).

SPIEWAK, Martin, Das ferne Echo der Vernunft: das höhere Bildungswesen in Hispanoamerika im Zeitalter der Aufklärung (Münster, Hamburger Ibero-Amerika-Studien 3, 1993).

STOLLEIS, Michael, Judicial Interpretation in Transition from the Ancien Régime to Constitutionalism en Stolleis, Michael, Morigiwa, Yasutomo, Halpérin, Jean Louis, Interpretation of Law in the Age of Enlightenment. From the Rule of the King to the Rule of Law (London, 2011).

SCHORn SCHÜtTe, Luise, Kommunikation über Politik im Europa der Frühen Neuzeit, en Jahrbuch des Historischen Kollegs (2007).

Stone, M. F. W., Scholastics Schools and Early Modern Philosophy, en ÉL MISmo, The Cambridge Companion to early modern philosophy (Cambridge, Cambirdge University Press, 2006).

Thomasius, Christian, Historia algo más extensa del derecho natural de Christian Thomasius (Halle, 1719, trad. cast. Madrid, Tecnos, 1998).

Welzel, Hans, Die Naturrechtslehre Samuel Pufendorfs : e. Beitr. zur Ideengeschichte d. 17. u. 18. Jh. (Berlin, 1958).

WIESAND, Georg, Kurzer Entwurf einer Historie des Natur- und Völker-Rechts: nebst einigen Anmerkungen über die Unvollkommenheiten der natürlichen Rechtsgelehrsamkeit (Leipzig, 1759).

Wolf, Erik, Grosse Rechtdenker der deutschen Geistesgeschichte (Tübingen. J. C. B. Mohr, 1951).

Wunderer, Hartman, Staat und Herrschaft in der Frühen Neuzeit, (Stuttgart, Reclam, 2014).

Zurbuchen, Simon, Samuel Pufendorfs Theorie der Staatsformen und ihre Bedeutung für die Theorie der modernen Republik, en HüNING, Dieter, Naturrecht und Staatstheorie bei Samuel Pufendorf(Baden-Baden, Nomos, 2009). 